\title{
Caracterização fenotípica do perfil de resistência de bactérias isoladas da unidade de alimentação/nutrição em um hospital público de Recife-PE
}

\author{
Phenotypic characterization of the resistance profile of bacteria isolated from the feeding/nutrition \\ unit in a public hospital in Recife-PE
}

Caracterización fenotípica del perfil de resistencia de bacterias aisladas de la unidad de

alimentación/nutrición de un hospital público de Recife-PE

Recebido: 08/04/2021 | Revisado: 15/04/2021 | Aceito: 23/04/2021 | Publicado: 08/05/2021

\author{
Roberta Carolline de Oliveira Silva \\ ORCID: https://orcid.org/0000-0002-3891-2545 \\ Universidade Federal de Pernambuco, Brasil \\ E-mail: carolline_nutri@hotmail.com \\ Isabel Cristina Silva \\ ORCID: https://orcid.org/0000-0001-8806-9157 \\ Universidade Federal de Pernambuco, Brasil \\ E-mail: bel.enfermagem.ufpe @ hotmail.com \\ Sandrelli Meridiana de Fátima Ramos dos Santos Medeiros \\ ORCID: https://orcid.org/0000-0003-4051-0825 \\ Universidade Federal de Pernambuco, Brasil \\ E-mail: sandrelli_meridiana@hotmail.com \\ Sérgio Dias da Costa-Júnior \\ ORCID: https://orcid.org/0000-0002-2501-3284 \\ Universidade Federal de Pernambuco, Brasil \\ E-mail: sergio_dias16@hotmail.com \\ Lina Clara Gayoso e Almendra Ibiapina Moreno \\ ORCID: https://orcid.org/0000-0001-7244-7977 \\ Universidade Federal do Piauí, Brasil \\ E-mail: linaclaramoreno@gmail.com \\ Isabella Macário Ferro Cavalcanti \\ ORCID: https://orcid.org/0000-0002-7889-3502 \\ Universidade Federal de Pernambuco, Brasil \\ E-mail: isabella.cavalcanti@ufpe.br
}

\begin{abstract}
Resumo
O presente estudo teve como objetivo determinar o perfil de resistência de bactérias isoladas das superfícies e utensílios da unidade de alimentação e nutrição de um hospital público na cidade de Recife-PE. Amostras de superfícies foram coletadas, transferidas para o meio caldo Infusão Cérebro Coração (BHI) e incubadas a $35^{\circ} \mathrm{C}$ por 24 h. Após a identificação de Staphylococcus aureus, Enterococcus spp. e enterobactérias, os perfis de resistência foram determinados de acordo com o Clinical and Laboratory Standards Institute. Das 10 amostras coletadas, 6 apresentaram bactérias Gram-positivas e todas apresentaram enterobactérias. Staphylococcus aureus resistente à meticilina (MRSA) estava presente no balcão de preparo de lanches e sobremesas e no balcão de frios. Os locais que apresentaram maior quantidade de microrganismos resistentes foram a pia de lavagem de pratos com as espécies Klebsiella pneumoniae (ESBL e MBL), Salmonella spp. (KPC) e Providencia spp.; balcão de preparo de lanches e sobremesas com Klebsiella pneumoniae (ESBL) e Salmonella spp. (ESBL e KPC); e balcão de finalização de refeições com Providencia spp. e Citrobacter spp. (MBL). Superfícies, equipamentos e mãos de manipuladores de alimentos são fontes de contaminação por bactérias com perfis de resistência, fazendo-se necessária a implementação e supervisão das boas práticas de higienização de superfícies, equipamentos e mãos de manipuladores, assim como medidas educativas na unidade de alimentação e nutrição do hospital.
\end{abstract}

Palavras-chave: Segurança alimentar sanitária; Resistência bacteriana a antibióticos; Unidades hospitalares.

\begin{abstract}
To determine the resistance profile of bacteria isolated from surfaces and utensils of the food and nutrition unit of a public hospital in the city of Recife-PE. Surface samples were collected, transferred to the Brain Heart Infusion (BHI) broth, and incubated for $24 \mathrm{~h}$ at $35{ }^{\circ} \mathrm{C}$. After the identification of Staphylococcus aureus, Enterococcus spp. and enterobacteria, resistance profiles were determined according to the Clinical and Laboratory Standards Institute. Among the 10 samples collected, 6 presented Gram-positive bacteria and all showed enterobacteria. Methicillinresistant Staphylococcus aureus (MRSA) was present at the snack and dessert preparation counter and the cold cuts
\end{abstract}


counter. The sites with the highest number of resistant microorganisms were the dishwashing sink with the species Klebsiella pneumoniae (ESBL and MBL), Salmonella spp. (KPC) and Providencia spp.; snack and dessert table with Klebsiella pneumoniae (ESBL) and Salmonella spp. (ESBL and KPC); and dining counter with Providencia spp. and Citrobacter spp. (MBL). Surfaces, equipment, and hands of food handlers are sources of contamination by bacteria with resistance profiles, making it necessary the implementation and supervision of good practices of cleaning surfaces, equipment and hands of handlers, as well as educational measures in the hospital's food and nutrition unit.

Keywords: Food safety; Drug resistance; Hospital units.

\section{Resumen}

El presente estudio tuvo como objetivo determinar el perfil de resistencia de bacterias aisladas de las superficies y utensilios de la unidad de alimentación y nutrición de un hospital público de la ciudad de Recife-PE. Se recogieron muestras de superficie, se transfirieron a caldo de infusión de cerebro y corazón (BHI) y se incubaron a $35^{\circ} \mathrm{C}$ durante 24 h. Después de la identificación de Staphylococcus aureus, Enterococcus spp. y enterobacterias, los perfiles de resistencia se determinaron de acuerdo con el Clinical and Laboratory Standards Institute. De las 10 muestras recolectadas, 6 tenían bacterias Gram positivas y todas tenían enterobacterias. Staphylococcus aureus resistente a la meticilina (MRSA) estuvo presente en el mostrador de preparación de bocadillos y postres y en el buffet frío. Los lugares que mostraron mayor cantidad de microorganismos resistentes fueron el fregadero para lavar platos con las especies Klebsiella pneumoniae (BLEE y MBL), Salmonella spp. (KPC) y Providencia spp.; mostrador para la preparación de snacks y postres con Klebsiella pneumoniae (BLEE) y Salmonella spp. (BLEE y KPC); y mostrador de finalización de comidas con Providencia spp. y Citrobacter spp. (MBL). Las superficies, el equipo y las manos de los manipuladores de alimentos son fuentes de contaminación por bacterias con perfiles de resistencia, lo que hace necesarias prácticas de higiene adecuadas para una alimentación libre de contaminantes.

Palabras clave: Seguridad alimentaria sanitária; Resistencia bacteriana a los antibióticos; Unidades hospitalarias.

\section{Introdução}

O termo "segurança alimentar" faz referência a uma garantia de condições para uma alimentação adequada à saúde (Machado et al., 2018). No Brasil, este termo é utilizado para dar ênfase ao aspecto qualitativo e quantitativo do alimento (de Castro, 2019). A incidência de doenças transmitidas por alimentos (DTA) vem crescendo gradualmente, e estas constituem um dos problemas de saúde pública mais frequente do mundo. Essas doenças são causadas principalmente por microrganismos que penetram no organismo humano através da ingestão de água e alimentos contaminados (Guimarães et al., 2018).

A Organização Mundial de Saúde (OMS) estima que as DTAs acometam 1 a cada 10 pessoas, resultando em cerca de 600 milhões de doentes e 420 mil mortos por ano no mundo (OPAS, 2020). No Brasil são notificados em média 700 surtos de DTAs todos os anos, com envolvimento de 13 mil doentes (Ministério da Saúde, 2020).

Os sintomas observados nessas patologias vão desde manifestações leves como dor de estômago, náusea, vômitos, diarreia e febre, até ocorrências mais sérias como desidratação grave, diarreia sanguinolenta, insuficiência renal aguda e insuficiência respiratória (Yousaf et al., 2019). Dentre as causas mais frequentes de contaminação de alimentos estão a conservação inadequada, a contaminação cruzada, e a manipulação incorreta de alimentos crus e processados (Almeida et al., 2013).

Alguns microrganismos estão envolvidos em intoxicações alimentares, como por exemplo, Staphylococcus aureus, Enterococcus spp. e as enterobactérias. Esses microrganismos são identificados em ambientes hospitalares e os perfis de resistência a agentes antimicrobianos associados a esses patógenos vêm crescendo. Os principais perfis de resistência são Staphylococcus aureus resistente à meticilina (MRSA), Staphylococcus aureus resistente a macrolídeos, lincosamida e estreptograminas B (MLSB), Enterococcus resistente à vancomicina (VRE), bactérias produtoras de beta-lactamases de espectro estendido (ESBL), bactérias produtoras da enzima identificada na Klebsiella pneumoniae carbapenemase (KPC) e bactérias produtoras de metalo-beta-lactamase (MBL) (Khan et al., 2018).

A rápida disseminação de bactérias com perfil de resistência é uma ameaça em potencial para os tratamentos baseados em antibióticos atualmente disponíveis (Jubeh et al., 2020). Na unidade de alimentação e nutrição uma das principais fontes de contaminação é a superfície em que o alimento ou o manipulador entra em contato, pois podem abrigar bactérias que 
contaminam os alimentos (Silva et al., 2015). Assim as condições de higiene do ambiente, dos equipamentos, das superfícies e dos utensílios podem contribuir de forma positiva ou negativa para a qualidade do alimento.

Sabe-se que a resistência a antimicrobianos tem aumentado no Brasil e que a identificação precoce dos microrganismos, em especial os que apresentam perfil de resistência, é fundamental para alertar os profissionais de saúde em relação às possíveis fontes de contaminação hospitalar (Moura et al., 2019). Nesse contexto, o presente artigo teve por objetivo identificar bactérias com perfil de resistência em superfícies e utensílios utilizados na unidade de alimentação e nutrição de um hospital público na cidade de Recife - PE.

\section{Metodologia}

\subsection{Tipo de estudo}

Trata-se de um estudo experimental de caráter descritivo que visa a coleta de amostras de superfícies e equipamentos usados na unidade de alimentação e nutrição de um hospital para posterior identificação de bactérias com perfil de resistência.

\subsection{Local do estudo}

Pesquisa realizada na Unidade de Alimentação e Nutrição (UAN) de um hospital público na cidade de Recife - PE.

\subsection{Coleta das Amostras}

Inicialmente, as amostras de superfícies inanimadas como balcão de distribuição de frios, balcão de preparo de lanches e sobremesas, balcão de finalização de refeições, caixotes de armazenamento de pães, carrinho de distribuição de dietas, câmara de frios, talheres, pia de lavagem de mãos, pia de lavagem de pratos e dispensador de sabão de um hospital público da cidade de Recife-PE foram coletadas em 2016 com o auxílio de swab e transferidas para caldo BHI para as devidas análises.

\subsection{Análise das Amostras}

\subsubsection{Identificação de Staphylococcus aureus e Enterococcus spp.}

Para a identificação das bactérias Gram-positivas, as amostras que estavam no BHI foram incubadas a $35 \pm 2{ }^{\circ} \mathrm{C}$ por 24 h. Após crescimento microbiano as amostras foram semeadas em Ágar sangue e Ágar Baird Parker e novamente incubadas a $35 \pm 2{ }^{\circ} \mathrm{C}$ por $24 \mathrm{~h}$. Após incubação, as colônias foram submetidas à coloração de Gram e às provas da catalase, coagulase, DNAse, Ágar manitol salgado, bile esculina e cloreto de sódio $(\mathrm{NaCl})$ a 6,5\% para confirmação da presença de Staphylococcus aureus e Enterococcus spp. (Konemam et al., 2008).

\subsubsection{Identificação das enterobactérias}

Para a identificação das enterobactérias, após crescimento microbiano em caldo BHI, as amostras foram semeadas em Ágar MacConkey e Ágar SS e incubadas por 24 h a $35^{\circ} \mathrm{C}$. Após a incubação, as colônias foram submetidas às provas bioquímicas para a confirmação da presença deste grupo bacteriano (Konemam et al., 2008). Foram realizadas as provas de oxidase, lisina, ureia, citrato, tríplice açúcar ferro (TSI), motilidade-indol-ornitina (MIO), fenilalanina, DNase, sacarose e arabinose.

\subsubsection{Identificação dos perfis de resistência MRSA, MLSB e VRE}

Após a identificação do Staphylococcus aureus e Enterococcus spp., os perfis de resistência dos Staphylococcus aureus resistente à meticilina (MRSA), Staphylococcus aureus resistente a macrolídeos, lincosamida e estreptograminas B 
(MLSB) e Enterococcus spp. resistente à vancomicina (VRE) foram determinados de acordo com o Clinical and Laboratory Standards Institute (CLSI, 2016).

As amostras positivas para $S$. aureus, foram submetidas ao método de difusão em disco com cefoxitina, assim como o teste com ágar screening para oxacilina para a identificação de MRSA. Para o método da difusão em disco foram preparados inóculos dos microrganismos ajustados em 0,5 da escala de McFarland e semeados em ágar Müeller Hinton (MHA). Posteriormente, os discos de cefoxitina foram depositados nas placas que foram incubadas a $35{ }^{\circ} \mathrm{C}$ por $24 \mathrm{~h}$. As amostras foram analisadas seguindo os pontos de corte do CLSI ${ }^{13}$. No teste de ágar screening para oxacilina, inicialmente foram preparadas placas de MHA contendo $4 \%$ de $\mathrm{NaCl}$ e $6 \mu \mathrm{g} / \mathrm{mL}$ de oxacilina. Em seguida foram preparados inóculos dos microrganismos ajustados em 0,5 da escala de McFarland e semeados nestas placas. Por fim, as placas foram incubadas por $35^{\circ} \mathrm{C}$ por $24 \mathrm{~h}$. As placas foram cuidadosamente observadas contra a luz e qualquer crescimento após $24 \mathrm{~h}$ foi considerado resistente à oxacilina, consequentemente MRSA. Foram utilizados como controles dos experimentos as cepas S. aureus ATCC 25923 e MRSA ATCC 33591.

O fenótipo de resistência MLSB foi detectado através do teste D. Após o ajuste do inóculo como descrito acima, os discos de eritromicina e clindamicina foram distribuídos a uma distância de $20 \mathrm{~mm}$ entre os discos. Posteriormente as placas foram incubadas por $35^{\circ} \mathrm{C}$ por $24 \mathrm{~h}$ e após incubação os isolados que não apresentaram achatamento do halo de clindamicina foram relatados como sensíveis à clindamicina (teste D negativo) e os isolados que apresentaram achatamento do halo de clindamicina adjacente ao disco de eritromicina (Halo "D") indicaram resistência induzível à clindamicina (teste D positivo). Foram utilizados como controles dos experimentos as cepas S. aureus ATCC 25923 e um isolado clínico de S. aureus portador do gene ermA.

Após a identificação do Enterococcus spp., o VRE foi determinado através do método de difusão em disco com teicoplanina e vancomicina, assim como o teste com ágar screening para vancomicina de acordo com o CLSI (CLSI, 2016). No teste de ágar screening para vancomicina, inicialmente foram preparadas placas de BHI contendo e $6 \mu \mathrm{g} / \mathrm{mL}$ de vancomicina. Em seguida foram preparados inóculos dos microrganismos ajustados em 0,5 da escala de McFarland e semeados nestas placas. Por fim, as placas foram incubadas por $35{ }^{\circ} \mathrm{C}$ por $24 \mathrm{~h}$. As placas foram cuidadosamente observadas contra a luz e qualquer crescimento após 24 h foi considerado resistente à vancomicina, consequentemente VRSA.

\subsubsection{Identificação dos perfis de resistência KPC, ESBL e MBL}

Para a identificação de bactérias produtoras de betalactamases de espectro estendido (ESBL), os métodos utilizados foram difusão em disco com antibióticos e teste da aproximação (El-Hady \& Adel, 2015). Nas duas situações os inóculos foram ajustados em 0,5 da escala de McFarland e semeados em MHA. Para o teste de difusão em disco foram utilizados ceftazidima, cefotaxima e cefpodoxima e para o teste da aproximação foram distribuídos os discos de ceftazidima, amoxicilina com ácido clavulânico e aztreonam a uma distância de 20-25 mm entre os discos. Por fim, as placas foram incubadas por $35^{\circ} \mathrm{C}$ por $18 \mathrm{~h}$ e após incubação o surgimento de um halo de inibição adicional entre o disco contendo ácido clavulânico e qualquer disco de cefalosporina e/ou aztreonam (ghost-zone) foi considerado como positivo para produção de ESBL. Foram utilizados como controle do experimento as cepas de E. coli ATCC 25922 e Klebsiella pneumoniae ATCC 700603.

O perfil fenotípico KPC foi identificado através do método de difusão em disco com carbapenêmicos, assim como pelo teste de Hodge. Para o método de difusão em disco foram preparados inóculos dos microrganismos ajustados em 0,5 da escala de McFarland e semeados em MHA. Posteriormente, os discos de ertapenem, imipenem e meropenem, foram depositados nas placas que foram incubadas a $35{ }^{\circ} \mathrm{C}$ por $18 \mathrm{~h}$. As amostras foram analisadas através dos halos de inibição seguindo os pontos de corte do CLSI (CLSI, 2016). Para o teste de Hodge, inicialmente a E. coli ATCC 25922 foi ajustada em 
0,5 da escala de McFarland, diluída 10 vezes e semeada em MHA. Posteriormente, o disco de meropenem foi depositado no centro da placa. Em seguida as bactérias testes foram inoculadas em linha reta a partir da borda do disco para a periferia da placa. Por fim, as placas foram incubadas por $35^{\circ} \mathrm{C}$ por $18 \mathrm{~h}$ e o resultado foi baseado na distorção dos halos de inibição.

Para a identificação de MBL foi utilizado o método de difusão em disco com antibióticos associado a uma substância quelante. Novamente o inóculo foi ajustado no 0,5 da escala de McFarland, semeado em MHA e os discos de imipenem, e meropenem embebidos em EDTA a $0,1 \mathrm{~N}$ foram depositados nas placas. As placas foram então incubadas por $18 \mathrm{~h}$ a $35^{\circ} \mathrm{C} \mathrm{e}$ em seguida foi observada a diferença entre o tamanho do halo de inibição dos antimicrobianos com e sem o EDTA. A presença de uma diferença entre os halos de inibição $>5 \mathrm{~mm}$ foi considerado como fator determinante para a confirmação de cepas MBL (CLSI, 2016).

\subsection{Aspectos éticos}

O presente trabalho não precisou da aprovação no comitê de ética, pois não houve contato com os pacientes, já que as amostras foram coletadas de superfície do hospital público. O projeto foi submetido à autorização do hospital público onde os experimentos foram realizados e recebeu o parecer favorável para a sua execução.

\section{Resultados}

Após a realização da identificação dos microrganismos, das 10 amostras coletadas, 6 apresentaram bactérias Grampositivas (60\%) e todas as amostras apresentaram enterobactérias (100\%) (Tabela 1 e Tabela 2). Quanto às bactérias Grampositivas (Tabela 1), 3 amostras apresentaram Staphylococcus aureus (balcão de preparo de lanches e sobremesas, balcão de finalização de refeições e balcão de distribuição de frios), 1 apresentou Staphylococcus spp. coagulase-negativo (talheres), 1 Enterococcus spp. (caixotes de armazenamento de pães) e 1 Staphylococcus aureus e Staphylococcus spp. coagulase-negativo simultaneamente (dispensador de sabão). O carrinho de distribuição de dietas, a câmara de frios, a pia de lavagem de mãos e a pia de lavagem de pratos não apresentaram contaminação por bactérias Gram-positivas.

Tabela 1. Identificação de bactérias Gram-positivas em superfícies e utensílios utilizados na unidade de alimentação e nutrição de um hospital público na cidade de Recife - PE.

\section{Prevalência de colonização $\quad$ Gênero/Espécie Bacteriana $\quad$ Prevalência por gênero/espécie $\mathrm{N} / \mathbf{n}$ total $(\%)$}

Staphylococcus aureus

$6 / 10(60 \%)$

$\begin{array}{lc}\begin{array}{l}\text { Staphylococcus spp. } \\ \text { coagulase-negativo }\end{array} & 1 / 6(16,7 \%) \\ \begin{array}{l}\text { Enterococcus spp. } \\ \text { Staphylococcus aureus }+\end{array} & 1 / 6(16,7 \%) \\ \begin{array}{l}\text { Staphylococcus spp. } \\ \text { coagulase-negativo }\end{array} & 1 / 6(16,7 \%)\end{array}$

Fonte: Autores (2021).

Quanto às enterobactérias, 28 cepas foram isoladas (Tabela 2), dentre elas: 6 amostras contendo Pseudomonas spp. (balcão de preparo de lanches e sobremesas, câmara de frios, no caixotes de armazenamento de pães, pia de lavagem de pratos, dispensador de sabão, pia de lavagem de mãos), 5 amostras com Salmonella spp. (balcão de preparo de lanches e sobremesas, 
câmara de frios, caixotes de armazenamento de pães, balcão de distribuição de frios e pia de lavagem de pratos), 4 amostras de Klebsiella pneumoniae (balcão de preparo de lanches e sobremesas, carrinho de distribuição de dietas, pia de lavagem de pratos e dispensador de sabão), 1 amostra de Shigella spp. (carrinho de distribuição de dietas), 3 amostras de Citrobacter spp. (caixotes de armazenamento de pães, balcão de finalização das refeições e dispensador de sabão), 3 amostras de Providencia spp. (pia de lavagem de pratos, balcão de finalização de refeições e talheres), 3 amostras de Enterobacter spp. (balcão de distribuição de frios, dispensador de sabão e talheres), 2 amostras de Serratia spp. (pia de lavagem de pratos e pia de lavagem de mãos) e 1 amostra com Proteus spp. (pia de lavagem de mãos).

Tabela 2. Identificação de enterobactérias em superfícies e utensílios utilizados na unidade de alimentação e nutrição de um hospital público na cidade de Recife - PE.

\begin{tabular}{lll}
\hline $\begin{array}{l}\text { Prevalência de colonização } \\
\text { N/n total (\%) }\end{array}$ & Gênero/Espécie Bacteriana & Prevalência por gênero/espécie \\
\hline & & \\
\hline & Pseudomonas spp. & $6 / 28(21,43 \%)$ \\
& Salmonella spp. & $5 / 28(17,86 \%)$ \\
& Klebsiella pneumoniae & $4 / 28(14,29 \%)$ \\
& Shigella spp. & $1 / 28(3,57 \%)$ \\
$10 / 10(100 \%)$ & Citrobacter spp. & $3 / 28(10,71 \%)$ \\
& Providencia spp. & $3 / 38(10,71 \%)$ \\
& Enterobacter spp. & $3 / 38(10,71 \%)$ \\
& Serratia spp. & $2 / 28(7,14 \%)$ \\
& Proteus spp. & $1 / 28(3,57 \%)$ \\
\hline
\end{tabular}

Fonte: Autores (2021).

Quanto à presença de bactérias Gram-positivas com perfil de resistência, foi encontrado 1 cepa de MRSA no balcão de preparo de lanches e sobremesas e 1 cepa no balcão de distribuição de frios. Nenhuma das amostras apresentou os fenótipos MLSB ou VRE.

Por outro lado, 12 cepas de enterobactérias com perfil de resistência $(42,9 \%)$ foram isoladas e identificadas (Tabela 3). Os locais que apresentaram microrganismos resistentes foram a pia de lavagem de pratos com as espécies Klebsiella pneumoniae ESBL e MBL, Salmonella spp. KPC; carrinho de distribuição de dietas com Klebsiella pneumoniae ESBL; Câmera de frios com Salmonella spp. resistente às cefalosporinas de $3^{\text {a }}$ geração e MBL; Caixotes de armazenamento de pães com Salmonella spp. KPC; Dispensador de sabão com Klebsiella pneumoniae KPC e MBL; Pia de lavagem de mãos com Proteus spp. (MBL); balcão de preparo de lanches e sobremesas com Klebsiella pneumoniae ESBL e Salmonella spp. resistente às cefalosporinas de $3^{\text {a }}$ geração e KPC); e balcão de finalização de refeições com Citrobacter spp. MBL. As superfícies dos talheres e do balcão de distribuição de frio não apresentaram bactérias com perfil de resistência. 
Tabela 3. Identificação de enterobactérias com perfil de resistência em superfícies e utensílios utilizados na unidade de alimentação e nutrição do Hospital das Clínicas, Recife - PE.

\begin{tabular}{|c|c|c|}
\hline $\begin{array}{l}\text { Prevalência de } \\
\text { colonização } \\
\text { N/n total }(\%)\end{array}$ & Gênero/Espécie Bacteriana com perfil de resistência & $\begin{array}{llll}\begin{array}{l}\text { Prevalência } \\
\text { resistência }\end{array} & \text { por } & \text { perfil } & \text { de } \\
\text { N/n total }(\%) & & & \\
\end{array}$ \\
\hline \multirow{9}{*}{$12 / 28(42,9 \%)$} & 2 Klebsiella pneumoniae (ESBL) & ESBL: \\
\hline & 1 Klebsiella pneumoniae (KPC e MBL) & $1 / 12(8,3 \%)$ \\
\hline & $\begin{array}{l}1 \text { Klebsiella pneumoniae (ESBL e MBL) } \\
1 \text { Salmonella spp. (resistência às cefalosporinas de } 3^{\text {a }} \\
\text { geração e KPC) }\end{array}$ & $\begin{array}{l}\text { MBL: } \\
3 / 12(25 \%)\end{array}$ \\
\hline & 1 Salmonella spp. MBL) & KPC: \\
\hline & 2 Salmonella spp. (KPC) & $2 / 12(16,7 \%)$ \\
\hline & 1 Citrobacter spp. (MBL) & KPC e MBL: \\
\hline & 1 Proteus spp. (MBL) & $1 / 12(8,3 \%)$ \\
\hline & & $\begin{array}{l}\text { Resistência às cefalosporinas de } 3^{\mathrm{a}} \\
\text { geração e KPC: } \\
1 / 12(8,3 \%)\end{array}$ \\
\hline & & $\begin{array}{l}\text { ESBL e MBL: } \\
1 / 12(8,3 \%)\end{array}$ \\
\hline
\end{tabular}

KPC: Klebsiella pneumoniae carbapenemase, ESBL: bactérias produtoras de betalactamases de espectro estendido; MBL: bactérias produtoras de metalobetalactamase. Fonte: Autores (2021).

\section{Discussão}

De acordo com os dados encontrados nesta pesquisa, a presença de Staphylococcus aureus em metade das amostras pode estar relacionada à capacidade de colonização de indivíduos saudáveis que esse microrganismo possui. Assim, os responsáveis pelo manuseio dos alimentos dessa unidade de nutrição podem ser portadores assintomáticos dessas cepas, além de outros indivíduos que transitarem nesses locais. Seja no preparo, transporte, distribuição ou comercialização de alimentos, a presença deste microrganismo é um indicativo de condições higiênico-sanitárias insatisfatórias (Aragão et al., 2020).

Em 2011, outro estudo identificou Staphylococcus aureus e Staphylococcus epidermidis em 8\% e 20\%, respectivamente, de bandejas térmicas da unidade de alimentação e nutrição de um hospital da cidade de Belo Horizonte-MG, sugerindo também a existência de condições higiênico-sanitárias insatisfatórias dos utensílios (Maia et al., 2011). Esses resultados são ainda mais alarmantes quando observamos que a combinação de um manipulador colonizado com determinada espécie de bactéria, associado à uma má higienização e má manipulação dos alimentos pode ser extremamente perigosa, podendo causar surtos de infecções alimentares (Soragni et al., 2019).

As cepas de Enterococcus spp. foram as bactérias menos isoladas no presente estudo (16,66\%). Similarmente um estudo realizado na área central do Município de Ibiúna-SP, analisou 30 lanchonetes escolhidas aleatoriamente (Soto et al., 2009). As coletas foram realizadas em superfícies de canudos de refrigerantes acondicionados em recipientes disponíveis no balcão, sem proteção individual, e em toda a superfície de contato do recipiente com os canudos, onde a exemplo do nosso estudo foi encontrado Enterococcus spp. em menor porcentagem.

Porém, são escassos os estudos que abordam a presença de bactérias resistentes em utensílios e superfícies inanimadas de unidades de nutrição de hospitais, pois a maior parte dos estudos estão voltados para a pesquisa desses microrganismos em unidades de atendimento direto aos pacientes. Sabe-se que a movimentação de profissionais de saúde dentro do ambiente hospitalar é uma das principais causas da disseminação de cepas resistentes entre as unidades de um hospital (Jácome et al., 2016). 
Um estudo realizado com 50 amostras obtidas de superfícies, utensílios e equipamentos de uma cozinha e um lactário hospitalar, resultou no isolamento de três colônias típicas de bactérias do gênero Listeria spp., cinco do gênero Salmonella spp. e oito do gênero Klebsiella spp. Os resultados da identificação bioquímica evidenciaram que seis amostras (12\%) estavam contaminadas com pelo menos uma das bactérias analisadas. Os isolados de Listeria spp. apresentaram resistência ao antibiótico cefoxitina e os isolados de Klebsiella spp. foram resistentes a ampicilina e amoxilina. Os isolados de Salmonella spp. foram sensíveis aos 13 antibióticos avaliados (Pinto et al., 2004). Quando comparado com o presente trabalho, podemos observar que as espécies Salmonella spp. e Klebsiella pneumoniae também foram as bactérias mais isoladas em outros estudos.

$\mathrm{Na}$ análise microbiológica das tábuas de corte de restaurantes comerciais de Santo André, SP, verificou-se a contaminação por Enterobacter spp., Proteus spp., Klebsiella spp., Serratia spp., Citrobacter spp., Yersinia spp., Escherichia coli e Shigella spp. (Sanches, 2007), perfil bacteriano que coincide com as enterobactérias isoladas na unidade de alimentação e nutrição hospitalar descritas no presente estudo. Os estudos de avaliação da presença de contaminação em unidades de nutrição estão voltados para a descrição das espécies bacterianas presentes nessas regiões, porém, é importante determinar o perfil de resistência desses microrganismos, afim de se obter dados que possibilitem comparar o perfil de susceptibilidade de microrganismos de diferentes unidades de um hospital. Esses resultados podem auxiliar na identificação de surtos epidemiológicos de cepas resistentes em determinados hospitais.

A resistência bacteriana a agentes antimicrobianos pode ser explicada não apenas pela presença de genes de resistência, mas também pela expressão desses genes que é controlada pelo meio ambiente. O uso indiscriminado de antibióticos torna os microrganismos resistentes aos agentes e, consequentemente, mais difíceis de serem eliminados (Tavares, 2014). Essa resistência é atualmente um dos maiores e mais consideráveis empecilhos para a saúde pública, uma vez que apesentam consequências graves tanto no ambiente hospitalar quanto na comunidade (Silva \& Aquino, 2018). O aparecimento e a dispersão das bactérias resistentes ocasionam obstáculos aos procedimentos clínicos, aumentam os custos do tratamento e as taxas de morbidade e mortalidade humana, uma vez que o tratamento destas bactérias é limitado e muitas vezes baseado na administração de doses elevadas de fármacos e com efeitos colaterais mais significativos (Costa \& Silva-Junior 2017).

As UANs de um hospital apresentam grande rotatividade de pessoas, desde acompanhantes de pacientes, a pacientes em estado crítico e imunodeprimidos. A contaminação cruzada e disseminação de patógenos ocorre quando, por exemplo, copeiras entregam refeições nos quartos dos pacientes, acompanhantes fazem suas refeições no refeitório usando utensílios que não são descartáveis e a desinfecção não é feita corretamente (Meyer \& Picoli, 2011). Desta forma, o controle higiênico da UAN favorece a exclusão de mais um risco diante dos diversos já existentes dentro de um ambiente hospitalar.

O presente estudo apresentou dados alarmantes de incidência de cepas de enterobactérias resistentes entre os isolados analisados. A presença de Salmonella sp. e Shigella sp. com resistência a cefalosporinas e carbapenêmicos foi reportada poucas vezes no mundo e esteve principalmente relacionada a alimentos derivados de animais (Day et al., 2015; Fernández et al., 2018). Além disso, a incidência de cepas KPC e MBL nas unidades de nutrição pode ser um fator indicador de disseminação clonal de isolados clínicos multirresistentes entre as unidades do hospital.

É importante ressaltar que crianças, idosos, pacientes hospitalizados e imunocomprometidos são mais susceptíveis a adquirir DTAs, devido principalmente a alterações no sistema imunológico, assim as condições higiênico-sanitárias na produção de refeições e na higienização de utensílios utilizados na UAN, principalmente os de uso compartilhado entre os pacientes com enfermidades diferentes, precisam de uma maior atenção e cuidado devido a maior vulnerabilidade do públicoalvo (Hanzen et al., 2019; Pena et al., 2019; Pieniz et al., 2019). 


\section{Considerações Finais}

Todas as amostras apresentaram contaminação por enterobactérias e/ou bactérias Gram-positivas e bactérias com perfil de resistência também foram isoladas. Esses resultados nos alertam para possíveis riscos de uma contaminação cruzada com bactérias com perfil de resistência, o que seria grave tendo em vista que as superfícies inanimadas e os utensílios analisados são locais de preparo e/ou armazenamento de alimentos direcionados a pacientes com a saúde fragilizada, ou mesmo imunodeprimidos. Uma vez que há uma lacuna nas pesquisas referente a caracterização do perfil fenotípico de resistência das bactérias isoladas de superfícies de unidades de alimentação hospitalar, existe a necessidade de uma atenção especial à análise da qualidade microbiológica nestes locais, fazendo-se necessária a implementação e supervisão das boas práticas de higienização de superfícies, equipamentos e mãos de manipuladores, assim como medidas educativas na unidade de alimentação e nutrição do hospital.

\section{Referências}

Almeida, J. C., Paula, C. M. S., Svoboda, W. K., Lopes, M. O., Pilonetto, M. P., Abrahão, W. M. \& Gomes, E. C. (2013). Perfil epidemiológico de casos de surtos de doenças transmitidas por alimentos ocorridos no Paraná, Brasil. Semina. Ciências Biológicas e da Saúde (Impresso): Ciências biológicas e da saúde, 34(1), 97-106.

Aragão, B. B., Trajano, S. C., Silva, J. G., Oliveira, J. M. B., Santos, A. S., Melo, R. P. B., Peixoto, R. \& Mota, R. (2020). Avaliação da contaminação por Staphylococcus aureus em queijo coalho artesanal elaborado com leite de cabra produzido no estado de Pernambuco. Arquivo Brasileiro de Medicina Veterinária e Zootecnia, 72(2), 615-622.

Clinical and Laboratory Standards Institute (CLSI) (2016). Performance Standards for Antimicrobial Susceptibility Testing. (27th ed.) (M100-S27). Wayne, PA.

Costa, A. L. P., Silva-Junior, A. C. S. (2017). Resistência bacteriana aos antibióticos e Saúde Pública: uma breve revisão de literatura. Estação Científica. (UNIFAP), 7(2), 45-57.

Day, M. R., Meunier, D., Doumith, M., de Pinna, E., Woodford, N. \& Hopkins, K. L. (2015). Carbapenemase-producing Salmonella enterica isolates in the UK. Journal of Antimicrobial Chemotherapy, 70(7), 2165-2167.

de Castro, R.R. (2019). The dissolution of the Brazilian National Food and Nutritional Security Council and the food and nutrition agenda. Cadernos de Saúde Pública, 35(2), e00009919.

El-Hady, S. A. \& Adel, L. A. (2015). Occurrence and detection of AmpC $\beta$-lactamases among Enterobacteriaceae isolates from patients at Ain Shams University Hospital. Egyptian Journal of Medical Human Genetics, 16(3), 239-244.

Fernández, J., Guerra, B. \& Rodicio, M. (2018). Resistance to carbapenems in non-typhoidal Salmonella enterica Serovars from humans, animals and food. Veterinary Sciences, 5(2), 40.

Guimarães, B. S., Ferreira, R. S. \& Soares LS. (2018). Perfil microbiológico de utensílios em unidade de alimentação e nutrição comercial e institucional de Salvador, BA. Higiene Alimentar, 201832 (284/285), 36-40.

Jubeh, B., Breijyeh, Z. \& Karaman, R. (2020). Resistance of gram-positive bacteria to current antibacterial agents and overcoming approaches. Molecules, 25(12), 2888.

Hanzen, I. P., Zanotelli, S. S. \& Zanatta, E. A. (2019). Diagnósticos, intervenções e resultados de enfermagem para subsidiar a consulta de enfermagem à criança. Enfermagem Foco, 10(7), 16-21.

Jácome, P. R. L., de Alves, L. R., Jácome-Júnior, A. T., Silva, M. J. B., Lima, J. L. C., Araújo, P. S. R., Lopes, A. C. S. \& Maciel, M. A. V. (2016). Detection of blaSPM-1, blaKPC, blaTEM and blaCTX-M genes in isolates of Pseudomonas aeruginosa, Acinetobacter spp. and Klebsiella spp. from cancer patients with healthcare-associated infections. Journal of Medical Microbiology, 65(7), 658-665.

Khan, A., Miller, W. R. \& Farias, C. A. (2018). Mechanisms of antimicrobial resistance among hospital-associated pathogens. Expert review of anti-infective therapy. Expert Review of Anti-infective Therapy, 16(4), 269-287.

Koneman, E. W., Winn, J. W., Allen, S. D., Janda, W. M., Schreckenberger, P. C., Winn, J. R., Procop, G. \& Woods, G. (2008). Diagnóstico Microbiológico: Texto e atlas colorido. (6th ed.), Guanabara Koogan.

Machado, M. L., Gabriel, C. G., Soar, C., das Neves, J. \& de Oliveira, J. T. C. (2018). State plan for food and nutrition security: potentialities and limitations. Revista de Nutrição, 31(4), 413-422.

Machado, J. R., Marson, J. M., Oliveira, A. C. S., Silva, P. R. \& Terra, A. P. S. (2009). Avaliação microbiológica das mãos e fossas nasais de manipuladores de alimentos da unidade de alimentação e nutrição de um hospital universitário. Revista da Faculdade de Medicina de Ribeirão Preto, 42(4), 461-465.

Maia, I. C. M. P., Monteiro, M. A. M., Fonseca, J. L., Coelho, M. R.. L. \& Lopes, S. L. C. (2011). Análise da contaminação de utensílios em unidades de alimentação e nutrição hospitalar no Município de Belo Horizonte-MG. Alimentos e Nutrição, 22(2), $265-271$. 
Meyer, G. \& Picoli, S. U. (2011). Fenótipos de betalactamases em Klebsiella pneumoniae de hospital de emergência de Porto Alegre. Jornal Brasileiro de Patologia e Medicina Laboratorial, 47(1), 25-31.

Ministério da Saúde. Doenças transmitidas por alimentos: causas, sintomas, tratamento e prevenção. [Citado 2020 Mai 18]. Disponível em: https://www.saude.gov.br/saude-de-a-z/doencas-transmitidas-por-alimentos

Moura, A. S., Souza, G. A., Alves, M. G., de Brito, M. V., Ladeira, L. M. C., Mendonça, V. F., Santos, M. \& Carvalho, M. T. M. (2019). Resistência bacteriana associada aos casos de infecção hospitalar na Santa Casa de Misericórdia de Passos (MG): estudo de caso. Ciência et Praxis. 11(21), 95-106.

OPAS- Organização Pan-Americana de Saúde. OMS- Organização Mundial da Saúde [Internet]. Segurança dos alimentos é responsabilidade de todos. https://www.paho.org/bra/index.php?option=com_content\&view=article\&id=5960:seguranca-dos-alimentos-e-responsabilidade-de-todos\&Itemid=875

Pena, S. B. S., Silva, A. C. G., Ramos, I. O., Barbosa, A. S. \& Studart, R. M. B. (2019). Atividades da vida diária de pacientes após transplante pulmonar. Enfermagem Foco 10(7), 70-75.

Pieniz, S., Rodrigues, D. F., Arndt, R. M., Mello, J. F., Rodrigues, K. L., Andreazza, R., F. A. O. Camargo, F. A. O. \& Brandellid, A. (2019). Molecular identification and microbiological evaluation of isolates from equipments and food contact surfaces in a hospital Food and Nutrition Unit. Brazilian Journal of Biology, 79, 191-200.

Pinto, U. M., Cardoso, R. R. \& Vanetti, M. C. D. (2004). Detecção de Listeria, Salmonella e Klebsiella em serviço de alimentação hospitalar. Revista de Nutrição, 17(3), 319-326.

Rossi, P., Kabuki, D. Y. \& Kuaye, A. Y. (2010). Avaliação microbiológica do preparo de fórmula láctea infantil em lactário hospitalar. Revista do Instituto Adolfo Lutz, 69(4), 503-509.

Sanches A. C. (2007). Avaliação do desenvolvimento microbiano em superfície de manipulação de alimentos. Higiene alimentar, 21 (154), 30-33.

Silva, L. C., dos Santos, D. B., de São José, J. F. B. \& da Silva, E. M. M. (2015). Boas práticas na manipulação de alimentos em Unidades de Alimentação e Nutrição. Demetra. Alimentação, Nutrição e Saúde, 10(4), 797-820.

Silva, M. O. \& Aquino, S. (2018). Resistência aos antimicrobianos: uma revisão dos desafios na busca por novas alternativas de tratamento. Revista de Epidemiologia e Controle de Infecção, 8(4), 472-482.

Soragni, L., Barnabe, A. S. \& Mello, T. R. C. (2019). Doenças transmitidas por alimentos e participação da manipulação inadequada para sua ocorrência: uma revisão. Estação Científica (UNIFAP), 9(2), 19-31.

Soto, F. R. M., Oliveira, E., Sakaguti, E. H., Fonseca, Y. S. K., Dias, H. G. G., Lopez, M. C. \& Azevedo, S. S. (2009). Contaminação bacteriana e fúngica de canudos de refrigerantes e seus recipientes em lanchonetes de município do interior de São Paulo. Revista de Nutrição, 22(6), 887-894.

Tavares, W. (2014). Antibióticos e quimioterápicos para o clínico. (3th ed.), Atheneu.

Yousaf, A.., Viveiros, B. \& Caron G. (2019). Rhode Island department of health foodborne illness complaint system: a descriptive and performance analysis. Journal of Food Protection, 82(9), 1568-1574. 